\title{
PON1 concentration and high-density lipoprotein characteristics as cardiovascular biomarkers
}

\author{
Fátima E. Murillo González ${ }^{1,2}$, Néstor Ponce-Ruíz ${ }^{1,2}$, Aurora E. Rojas-García1, \\ Yael Y. Bernal-Hernández ${ }^{1}$, Mike Mackness ${ }^{3}$, Jaime Ponce-Gallegos ${ }^{4}$, Guillermo Cardoso-Saldaña ${ }^{5}$, \\ Esteban Jorge-Galarza ${ }^{5}$, Margarita Torres-Tamayo ${ }^{5}$, Irma Martha Medina-Díaz ${ }^{1,2}$
}

\author{
'Universidad Autónoma de Nayarit, Laboratorio de Contaminación y Toxicología, \\ Nayarit, Mexico \\ 2Posgrado CBAP \\ ${ }^{3}$ DMiami Platja, Tarragona, Spain \\ ${ }^{4}$ Hospital Puerta de Hierro, Nayarit, México \\ 5Instituto Nacional de Cardiología-Ignacio Chávez, D.F.México, Mexico
}

Submitted: 28 January 2019

Accepted: 20 March 2019

Arch Med Sci Atheroscler Dis 2019; 4: e47-e54

DOI: https://doi.org/10.5114/amsad.2019.84447

Copyright $\odot 2019$ Termedia \& Banach

\section{Abstract}

Introduction: Serum paraoxonase 1 (PON1) is now known to be related to cardiovascular diseases (CVD). The aim of this study was to determine the relationship between PON1 concentration and high-density lipoprotein (HDL) subclasses in patients with proven CVD, cardiovascular risk factors but no CVD (CRF), and in healthy controls (control group).

Material and methods: A case-control study was carried out with 69 volunteers from the Mexican Institute of Social Security, Mexico. Clinical parameters, lipid profile, PON1 concentration, PON1 activities (AREase and CMPAase), and HDL subclasses were evaluated.

Results: Patients with CVD had significantly higher glucose and lower total cholesterol than the control group had $(p<0.01)$. AREase activity was not different between the control $(122.57 \pm 30.72 \mathrm{U} / \mathrm{ml})$, CRF $(115.81 \pm 32.81 \mathrm{U} / \mathrm{ml})$, and CVD $(109.34 \pm 29.60 \mathrm{U} / \mathrm{ml})$ groups. PON 1 concentration was significantly lower in CVD patients than in CRF and control patients $(p<0.001)$; a positive correlation was observed between AREase activity and PON1 concentration in the CVD group (Rho $=0.58 ; p<0.01$ ). Logistic regression analysis showed that the decrease in PON1 level was associated with the CVD group (RRR = $0.20 ; 95 \% \mathrm{Cl}: 0.09-0.45$ ) but not with the CRF group (RRR $=1.29 ; 95 \% \mathrm{Cl}$ : $0.89-1.90)$. Significant differences were observed in HDL $2 a$ and HDL $3 a$ concentrations between the control group and CRF and CVD groups $(p<0.05)$, but not between the CRF and CVD groups.

Conclusions: Our data suggest that PON1 status and HDL characteristics could be early biomarkers that predict the potential for developing CVD.

Key words: paraoxonase 1, cardiovascular diseases, high-density lipoprotein, PON1 concentration.

\section{Introduction}

Cardiovascular diseases (CVD) are disorders of the heart and blood vessels and include coronary heart disease, cerebrovascular disease, rheumatic heart disease, and other conditions [1]. It is estimated that 17.3 million people die from CVD each year (80\% of deaths occur in low-

\author{
Corresponding author: \\ Irma M. Medina Díaz \\ Laboratorio \\ de Contaminación \\ y Toxicología Ambiental \\ Secretaría \\ de Investigación \\ y Posgrado \\ Universidad Autónoma \\ de Nayarit \\ Tepic, 63155 Nayarit \\ México \\ Phone: +52 311-2118800, \\ 8919 \\ Fax: +52 3112118816 \\ E-mail: irmartha@hotmail.com
}


and middle-income countries), which makes it the leading cause of death in the world [2]. Individuals at risk of CVD may experience elevated blood pressure, glucose, and lipids as well as overweight and obesity [1].

It is well known that atherosclerosis is the underlying cause of coronary heart disease, which is a progressive disease characterized by the accumulation of lipids and fibrous elements in the large arteries. Epidemiological studies over the past 50 years have revealed numerous risk factors for atherosclerosis. The relative abundance of the different plasma lipoproteins appears to be of primary importance, because raised levels of atherogenic lipoproteins are a prerequisite for most forms of the disease [3]. It is well documented that high-density lipoprotein $(\mathrm{HDL})$ exerts a protective effect on the cardiovascular system, and serum HDL levels have been negatively associated with the risk of coronary artery disease (CAD) [4].

The HDL comprises a heterogeneous group of lipoproteins that are continually being remodeled and interconverted by plasma factors. In clinical practice, HDL concentration is determined as the simple concentration of cholesterol in circulating $\mathrm{HDL}$ particles (HDL-C); however, cholesterol is just one of more than 200 distinct molecular species of lipids in HDL and therefore does not represent a metric of atheroprotective HDL function. Indeed, $\mathrm{HDL}-\mathrm{C}$ is rather a nonfunctional surrogate marker for estimating HDL particle number and size, and does not reflect the heterogeneous composition and functionality of HDL [5].

The HDL comprises a heterogeneous group of lipoproteins that are continually being remodeled and interconverted by plasma factors. HDL particles may be classified by decreasing size as HDL2a, HDL2b, HDL3a, HDL3b and HDL3c. These HDL subclasses have a different capacity to promote cholesterol efflux from peripheral tissues, as well as different antioxidative properties [5-8]. Several proteins physically associated with HDL are involved in preventing lipid oxidation or the metabolism of lipid-hydroperoxides, including apoprotein A-1 (apoA1), lecithin, cholesterol acyltransferase (LCAT), platelet-activating factor acetylhydrolase (PAF-AH), and, in particular, paraoxonase 1 (PON1) [8-10].

Human serum PON1 is a $\mathrm{Ca}^{2+}$-dependent $\mathrm{HDL}$ associated ester hydrolase enzyme that protects low-density lipoprotein (LDL) and cell membranes from oxidation through hydrolysis of the biologically active lipid peroxides. Therefore, the antiatherogenic property of $\mathrm{HDL}$ is to a great extent conferred by PON1 and its capacity for preventing the formation of oxidized LDL $[4,11]$. The PON family comprises 3 members: PON1, PON2, and PON3. They are widely expressed in mammalian tissues.
PON2 is an exclusively intracellular antioxidant. PON1 and PON3 are located in the plasma associated with HDL. Both prevent LDL peroxidation in the circulation, conferring antagonistic effects against atherosclerosis development [4].

It has become increasingly noted in recent years that during disease development HDL becomes dysfunctional. That is, it is no longer able to prevent atherosclerosis but may even actually promote it [10]. Dysfunctionality of HDL can take the form of reduced cholesterol efflux capacity but is most commonly measured by the loss of anti-inflammatory/anti-oxidative function. The LDL added to endothelial cells in co-culture models becomes oxidized, inducing the production of monocyte chemotactic factors that increase monocyte binding and migration. The addition of $\mathrm{HDL}$ to the co-culture prevents oxidation of the LDL and impairs the inflammatory response [10]. Therefore, the need is growing to identify other HDL characteristics that better represent the function of these lipoproteins, which could be used as biomarkers of cardiovascular disease risk and to assess the clinical benefits of novel HDL-targeted therapies [9]. Most of the PON1 activity performed by HDL is found in the small HDL3 subfraction ( $3 a$, $3 b$, and $3 c$ ) [12]. It has been proposed that the structure of HDL is a key factor in keeping PON1 attached to the lipoprotein surface [9]. Therefore, low proportions of these subclasses could indicate low circulating plasma PON1.

Because factors such as low enzymatic activity and concentration of PON1 and a low proportion of HDL3 subfractions could indicate the decline of HDL antioxidant capacity, the aim of this study was to determine the relationship between PON1 concentration and HDL subclasses in patients with proven cardiovascular disease (CVD), cardiovascular risk factors but no CVD (CRF), and healthy controls (control group).

\section{Material and methods}

\section{Study subjects}

A case-control study was carried out with volunteers $(n=69)$ from the Mexican Institute of Social Security (IMSS) in Nayarit, Mexico. The patients were classified into 3 groups: 1) CVD, all participants had a documented diagnosis of chronic ischemic cardiovascular disease (previous myocardial infarction, coronary revascularization surgery, or coronary angioplasty). All patients in this group had carotid stenosis $\geq 70 \%$ based on ultrasound and they were evaluated and enrolled in this study during a stable phase of chronic ischemic cardiovascular disease by a medical cardiologist and all of them were free from ischemic events for at least 6 months $(n=26)$; 2) CRF, patients of this group had a documented 
diagnosis of hypertension (based on either clinic systolic and/or diastolic BP (SBP/DBP) $\geq 140 / 90$ $\mathrm{mm} \mathrm{Hg}$ but without CVD, diabetes, or renal disease. Some of them had dyslipidemia and were receiving treatment with statins $(n=22)$; and 3) control group, healthy subjects who attended a routine health check and had no coronary artery disease or chronic illness, as assessed by medical personnel and a questionnaire $(n=21)$. All subjects gave informed consent to participate in this study. The study was approved by the ethics committee of the Hospital Antonio González Guevara, Tepic Nayarit, Mexico (registry number COMBIOET/05/13). The CVD (76\%) and CRF (32\%) subjects were receiving treatment with statins; $15 \%$ and $9 \%$, respectively, took fibrates; $58 \%$ of CVD and $18 \%$ of CRF received $\beta$-blockers; $23 \%$ of CVD and $18 \%$ CRF took calcium antagonists, and $44 \%$ and $13 \%$ received aspirin treatment, respectively.

\section{Lipid profile assessment}

Intravenous blood samples after overnight fasting were obtained in EDTA, heparin, and dry tubes. Samples were centrifuged at $2500 \mathrm{rpm}$ for $25 \mathrm{~min}$ for the separation of serum and stored at $-80^{\circ} \mathrm{C}$ until analysis. Glucose in serum was determined in a certificated laboratory (ISO 9001 F-010). Total cholesterol, triglycerides, and high-density lipoprotein cholesterol (HDL-C) concentrations were determined in the plasma with enzymatic methods (Roche/Hitachi, Germany) in a COBAS c 311 auto-analyzer. Low-density lipoprotein cholesterol (LDL-C) was calculated with the Friedewald formula modified by DeLong [13]. The precision and accuracy of lipid and lipoprotein determinations were evaluated through the lipid and protein standardization program of the Center for Disease Control and Prevention (CDC) of the USA (LSP-CDC, Atlanta, GA. USA). Intra- and interassay variation coefficients were below $3 \%$.

\section{PON1 concentration}

Blood samples were collected in tubes containing EDTA and centrifuged for $25 \mathrm{~min}$ at $1500 \mathrm{rpm}$ to obtain plasma that was separated and stored at $-80^{\circ} \mathrm{C}$ until analysis. The PON1 concentration was determined by an enzyme-linked immunosorbent assay (ELISA) using a commercially available ELISA kit for human PON1 (SEA243Hu, CloudClone Corp., USA), according to the manufacturer's instructions.

\section{PON1 activity}

\section{Arylesterase activity}

The arylesterase (AREase) activity of PON1 was determined using phenylacetate as the substrate according to Eckerson et al. [14]. The initial rate of phenylacetate hydrolysis was measured in a cuvette containing $2.7 \mathrm{ml}$ of buffer $(10 \mathrm{Mm}$ Tris- $\mathrm{HCl}$, $40 \mu \mathrm{M}$ serine hemisulfate, $1 \mathrm{M} \mathrm{CaCl}_{2}, \mathrm{pH}$ 8) and $20 \mu \mathrm{l}$ of diluted plasma (1:50), and incubated for $5 \mathrm{~min}$ in the dark at room temperature. Subsequently, $300 \mu$ l of phenyl-acetate $(10 \mathrm{mM})$ was added and the absorbance change was monitored at $270 \mathrm{~nm}$ for $5 \mathrm{~min}$. The activity is expressed in $\mathrm{U} / \mathrm{ml}$ on the basis of the molar extinction coefficient of phenyl acetate $\left(1.31 \times 10^{3} \mathrm{M}^{-1} \mathrm{~cm}^{-1}\right)$. One unit of AREase activity is equivalent to $1 \mu \mathrm{mol}$ of phenylacetate hydrolyzed $/ \mathrm{min} / \mathrm{ml}$.

\section{CMPAase activity}

CMPAase activity was determined through 4-chloromethylphenylacetate (4-CMPA) hydrolysis, according to Richter et al. [15]. Plasma samples were diluted $1: 40$ in dilution buffer $(20 \mathrm{mM}$ Tris- $\mathrm{HCl}, 1 \mathrm{mM} \mathrm{CaCl}, \mathrm{pH}$ 8.0). The reaction mixture contained $60 \mu \mathrm{l}$ of plasma, $295.2 \mu \mathrm{l}$ of dilution buffer, and $304.8 \mu \mathrm{l}$ of 4-CMPA to a final concentration of $3 \mathrm{mM}$. The increase of absorbance was monitored at $280 \mathrm{~nm}$ for $5 \mathrm{~min}$ at $25^{\circ} \mathrm{C}$. The activity is expressed in $\mathrm{U} / \mathrm{ml}$ based on the molar extinction coefficient of the 4-CMPA hydrolysis product $\left(1.30 \mathrm{mM}^{-1} \mathrm{~cm}^{-1}\right)$.

\section{HDL subclasses}

HDL subclasses were analyzed using the method described by Medina-Urrutia et al. [16]. The HDL was separated from serum by ultracentrifugation at $10^{\circ} \mathrm{C}$ at $110,000 \mathrm{rpm}$ in an Optima Max ultracentrifuge at a density of $1.25 \mathrm{~g} / \mathrm{ml}$. The HDL samples were loaded into a 4-25\% polyacrylamide gradient gel. Gels were revealed for protein with Coomassie brilliant blue, scanned and digitalized in a GS-679 Bio-Rad densitometer and using the Bio-Rad image lab software for the analysis. Migration distance intervals of each gel were calculated by computing a standard curve of the protein-stainable HMW standards (thyroglobulin, $17 \mathrm{~nm}$; ferritin, $12.2 \mathrm{~nm}$; catalase, 10.4, $10.4 \mathrm{~nm}$; lactate dehydrogenase, $8.2 \mathrm{~nm}$; and albumin, $7.1 \mathrm{~nm}$ ) as a function of their relative migration distance. The relative proportion of each $\mathrm{HDL}$ was estimated within the following size intervals: HDL3c 7.21-7.76 nm; HDL3b 7.76-8.17 nm; HDL3a 8.17-8.77 nm; HDL2a 8.77-9.71 nm; and HDL2b 9.71-12.93 nm. The coefficients of variation of the subclasses were $5.50 \%, 3.09 \%, 3.25 \%, 3.45 \%$ and $4.40 \%$ for HDL2b, HDL2a, HDL3a, HDL3b, and $\mathrm{HDL} 3 c$, respectively. The average HDL particle size represents the overall distribution of the HDL subclasses and was calculated as the average size of each HDL subclass interval ( $\mathrm{nm}$ ), multiplied by its relative area under the densitometric scan. The 
F.E. Murillo González, N. Ponce-Ruíz, A.E. Rojas-García, Y.Y. Bernal-Hernandez, M. Mackness, J. Ponce-Gallegos, G. Cardoso-Saldaña, E. Jorge-Galarza, M. Torres-Tamayo, I.M. Medina-Díaz

coefficient of variation of the average HDL particle size was $0.24 \%$.

\section{Statistical analysis}

Statistical analyses were performed using Stata 11 and GraphPad Prism 5.0. The compatibility of the continuous variables with normal distribution was evaluated using the skewness and kurtosis test. Descriptive analysis data are presented as mean \pm SD for parametric data, and median with interquartile range for nonparametric data. Normally distributed continuous variables were compared using one-way analysis of variance (ANOVA), applying the Bonferroni correction for multiple comparisons, whereas the Kruskal-Wallis and Dunn tests were used for non-normally distributed continuous variables in independent samples. The $\chi^{2}$ test was used to evaluate the significance of parameters expressed in frequencies. The Spearman test was used to evaluate correlations among non-parametric variables. The average diameter of HDL was categorized in tertiles in each group. The associations between HDL subclasses, PON1 activities and other parameters were evaluated by logistic regression analysis, and the interactions for dyslipidemia and obesity were analyzed. The statistical significance level was accepted as $p<0.05$.

\section{Results}

\section{Lipid profile}

Table I shows the clinical and biochemical characteristics of the study population. Sex and age were similar among groups. A significant difference was noted in BMI and systolic blood pressure between the control and CRF groups $(p<0.05)$. Of the study population, $60 \%$ had BMI values higher than that considered normal by the World Health Organization. Patients with CVD had significantly higher glucose and lower total cholesterol than the control group had. In contrast, LDL-C and ApoB were higher than in CRF and control groups; $76 \%$ of the CVD group and $32 \%$ of the CRF group were receiving statin therapy $(p<0.01)$.

\section{PON1 enzymatic activity}

As shown in Table I, AREase activity was not different between the control $(122.57 \pm 30.72 \mathrm{U} / \mathrm{ml})$, CRF $(115.81 \pm 32.81 \mathrm{U} / \mathrm{ml})$, and CVD $(109.34 \pm 29.60$ $\mathrm{U} / \mathrm{ml}$ ) groups. However, we found a positive correlation between AREase activity and PON1 concentration in the CVD group (rho $=0.58 ; p<0.01$ ) and control (rho $=0.43 ; p=0.04$ ) groups, but not for the CRF (rho $=0.28 ; p=0.19$ ) group (data not shown). Likewise, the CMPAase activity was not different between the control $(17.68 \pm 3.87 \mathrm{U} / \mathrm{ml})$,
CRF (17.69 $\pm 4.26 \mathrm{U} / \mathrm{ml})$, and CVD (15.67 \pm 5.44 $\mathrm{U} / \mathrm{ml}$ ) groups (Table I). CMPAase activity was not correlated with PON1 concentration (control rho $=$ 0.013, $p=0.95$; CRF rho $=-0.378, p=0.09$; and CVD rho $=0.229, p=0.27$ ). The data did not show an association between PON1 activities and HDL subclasses.

\section{PON1 concentration}

PON1 concentration was 0.52 and 0.52 times lower in CVD patients, with respect to control and CRF groups ( $p<0.001)$ (Figure 1$)$. These results are supported by a logistic regression analysis that showed that the decrease in PON1 level was associated with the CVD group (RRR $=0.20$, 95\% Cl: $0.09-0.45)$ but not with the CRF group $(\mathrm{RRR}=1.29,95 \% \mathrm{Cl}:$ 0.89-1.90). However, after adjusting for obesity and dyslipidemia status, we observed that the increase in the concentration of PON1 was associated with a decreased risk of belonging to the CVD group. Therefore, obesity could be the underlying cause of this increased risk (Table II).

\section{HDL subclasses}

HDL $2 b$ was found to have similar proportions among the groups $(p=0.07)$ (Figure 2). Significant differences were observed in HDL $2 a$ and $\mathrm{HDL} 3 \mathrm{a}$ between the control group and CRF and CVD groups $(p<0.05)$ but not between the CRF and CVD groups. The opposite was observed in the smallest HDL subclasses, HDL3b and HDL3c, because the largest proportions were found in the control group compared with the CVD group $(p<0.02)$. Regarding HDL3b, no significant differences existed between CRF and CVD patients, or in $\mathrm{HDL} 3 \mathrm{c}$ between the control group and CRF.

Figure 3 shows the average diameter size of $\mathrm{HDL}$ in the different groups. In general, the control group had HDLs with smaller diameters than those in the CRF and CVD groups. The CRF and CVD groups did not have differences in HDL size.

Multinomial logistic regression analysis showed that the increase in the average size of $\mathrm{HDL}$ is a factor that may increase the possibility of belonging to the CVD group, regardless of the presence or absence of obesity or dyslipidemia (Table III). On the other hand, increases in the average diameter plus the presence of dyslipidemia were not associated with increased risk of belonging to the CRF group. In addition, the risk of belonging to this group increases as the diameter of the HDL increases, and this does not depend on the obesity status (Table III).

Additionally, comparisons were made between PON1 levels and HDL size (categorized in tertiles, data not shown) in each study group. We found that in the control group, the first tertile had a sig- 
Table I. Clinical and biochemical characteristics in the study groups

\begin{tabular}{|c|c|c|c|c|}
\hline Parameter & Control $(n=21)^{\mathrm{a}}$ & $\operatorname{CRF}(n=22)^{\mathrm{b}}$ & $\operatorname{CVD}(n=26)^{\mathrm{c}}$ & $P$-value \\
\hline \multicolumn{5}{|l|}{ Anthropometrics: } \\
\hline Men/women & $11 / 10$ & $7 / 15$ & $11 / 15$ & $0.39^{\star * *}$ \\
\hline Age [years] & $61.90 \pm 12.28$ & $59.68 \pm 16.16$ & $65.15 \pm 11.64$ & $0.37^{*}$ \\
\hline \multicolumn{5}{|l|}{ Physiological: } \\
\hline $\mathrm{BMI}\left[\mathrm{kg} / \mathrm{m}^{2}\right]$ & $27.00(24.31-29.77)$ & $30.04(28.08-34.90)^{a}$ & $29.56(26.66-33.71)$ & $0.04^{\star *}$ \\
\hline $\mathrm{BMI} \geq 25 \mathrm{~kg} / \mathrm{m}^{2}(\%)$ & 61.90 & 90.90 & 80.77 & $0.08^{\star * *}$ \\
\hline Diastolic pressure $[\mathrm{mmHg}]$ & $80(75-80)$ & $80(70-80)$ & $70(70-80)^{b}$ & $0.02^{* *}$ \\
\hline Systolic pressure [mm Hg] & $120(110-120)$ & $130(120-140)^{\mathrm{a}}$ & $120(110-130)$ & $0.02^{* *}$ \\
\hline Previous diagnosis of hypertension (\%) & 0 & $100^{\mathrm{a}}$ & $88.50^{\mathrm{a}}$ & $<0.001^{\star * *}$ \\
\hline Diabetes diagnosis (\%) & 0 & 0 & $50^{\mathrm{ab}}$ & $<0.001^{\star * *}$ \\
\hline Total dyslipidemia (\%) & 66.70 & 54.50 & $26.90^{\mathrm{a}, \mathrm{b}}$ & $0.02^{\star \star *}$ \\
\hline Total cholesterol > 200 mg/dl (\%) & 66.70 & 59.10 & $19.20^{\mathrm{a}, \mathrm{b}}$ & $<0.01^{\star * *}$ \\
\hline Triglycerides > 150 mg/dl (\%) & 38.10 & 54.50 & 42.30 & $0.52^{\star * \star}$ \\
\hline HDL-C < 40 in men (\%) & 54.50 & 57.10 & 72.70 & $0.71^{\star \star *}$ \\
\hline HDL-C < 50 in women (\%) & 60.00 & 60.00 & 66.70 & $0.92^{\star \star \star}$ \\
\hline \multicolumn{5}{|l|}{ Harmful habits (\%): } \\
\hline Current smoking & $14.29^{b c}$ & 0 & 0 & $0.02^{\star \star \star}$ \\
\hline Past smoking & 28.57 & 40.91 & 50 & $0.33^{* * *}$ \\
\hline Current alcohol drinking & 52.38 & 50 & 26.92 & $0.14^{\star \star \star}$ \\
\hline Past alcohol drinking & 57.14 & 62.50 & 70.59 & $0.73^{\star \star \star}$ \\
\hline \multicolumn{5}{|l|}{ Biochemical parameters [mg/dl]: } \\
\hline Glucose & $96(89-104)$ & $100.5(90-108)$ & $113(91-132)^{a}$ & $0.01^{\star \star}$ \\
\hline Total cholesterol & $213.61 \pm 43.36$ & $195.48 \pm 39.68$ & $161.50 \pm 50.93^{\mathrm{a}, \mathrm{b}}$ & $<0.001^{\star}$ \\
\hline LDL-C & $140.30 \pm 44.21$ & $123.51 \pm 36.51$ & $94.41 \pm 43.76^{\mathrm{a}, \mathrm{b}}$ & $<0.01^{*}$ \\
\hline Triglycerides & $140.6(95.4-198.9)$ & $155.75(106.4-214.2)$ & $137.45(96.6-209.7)$ & $0.71^{\star *}$ \\
\hline HDL-C & $42.5(35.9-53.1)$ & $42(35.7-53.8)$ & $39.85(35.9-47)$ & $0.70^{\star \star}$ \\
\hline ApoA1 & $142.62 \pm 20.97$ & $148.21 \pm 25.27$ & $135.35 \pm 23.81$ & $0.17^{\star}$ \\
\hline ApoB & $117.21 \pm 22.93$ & $107.14 \pm 28.25$ & $85.50 \pm 32.35^{\mathrm{a}, \mathrm{b}}$ & $<0.01^{\star}$ \\
\hline \multicolumn{5}{|l|}{ PON1: } \\
\hline Serum concentration $[\mu \mathrm{g} / \mathrm{ml}]$ & $6.06(4.6-6.7)$ & $6.07(5.75-7.34)$ & $3.21(2.76-3.95)^{a, b}$ & $<0.001^{\star *}$ \\
\hline AREase $[\mathrm{U} / \mathrm{ml}]$ & $122.57 \pm 30.72$ & $115.81 \pm 32.81$ & $109.34 \pm 29.60$ & $0.35^{\star}$ \\
\hline CMPAase $[\mathrm{U} / \mathrm{ml}]$ & $17.68 \pm 3.87$ & $17.69 \pm 4.26$ & $15.67 \pm 5.44$ & $0.24^{*}$ \\
\hline \multicolumn{5}{|l|}{ Pharmacotherapy (\%): } \\
\hline Statin & - & 32 & $76^{\mathrm{b}}$ & $0.01^{* * *}$ \\
\hline Fibrates & - & 9 & 15 & $0.51^{\star \star \star}$ \\
\hline$\beta$-blockers & - & 18 & 58 & $<0.001^{\star * *}$ \\
\hline Calcium antagonists & - & 13 & 44 & $<0.001^{* * *}$ \\
\hline
\end{tabular}

Results are expressed as mean $\pm S D$, percentage or median (interquartile range). $P$-values were calculated using ${ }^{*} A N O V A$ and Bonferroni tests, ${ }^{* * K r u s k a l-W a l l i s}$ and Dunn tests, or ${ }^{* * *} \chi^{2}$ test. ${ }^{a} p<0.05$ vs. control; ${ }^{b} p<0.05$ vs. CRF. 
F.E. Murillo González, N. Ponce-Ruíz, A.E. Rojas-García, Y.Y. Bernal-Hernandez, M. Mackness, J. Ponce-Gallegos, G. Cardoso-Saldaña, E. Jorge-Galarza, M. Torres-Tamayo, I.M. Medina-Díaz

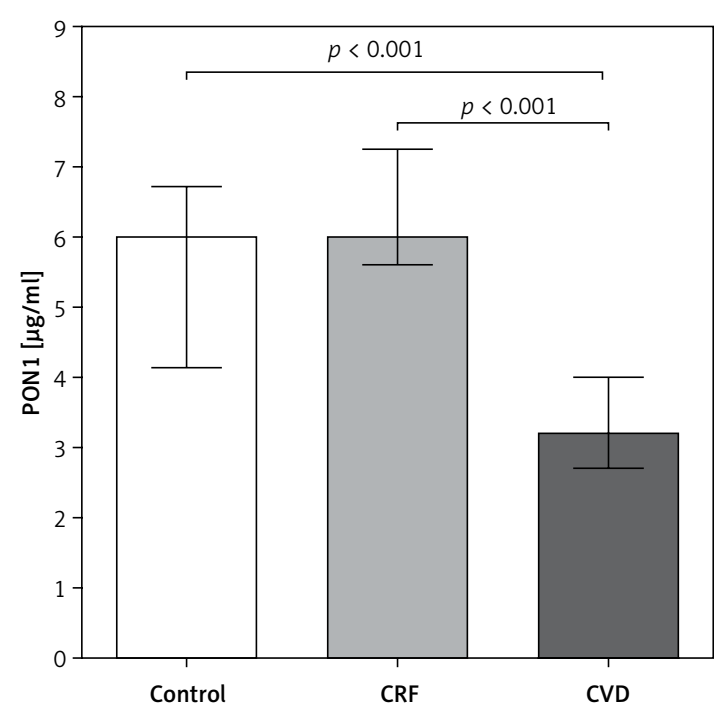

Figure 1. PON1 concentration levels among groups. Results are expressed as median (interquartile range). Comparisons between groups were made using Kruskal-Wallis and Dunn tests. Statistical significance level was accepted as $p<0.05$

nificantly higher PON1 concentration compared with the third tertile $(6.70 \mu \mathrm{g} / \mathrm{ml}$ and $4.62 \mu \mathrm{g} / \mathrm{ml}$, respectively). No significant differences by tertiles were observed in the CRF and CVD groups.

When analyzing the correlation of HDL size with triglyceride concentration, we observed a strong negative correlation (Rho $=-0.58, p=0.04$ ) only for patients with dyslipidemia belonging to the CRF group.

\section{Discussion}

The antioxidant and anti-inflammatory capacity of HDL is a feature of its beneficial impact on vascular health. Reductions in its capacity could contribute to dysfunctional HDL and increased vascular risk [17]. Defining functions of HDL subpopulations and their dysfunctions are of particular interest for refining our understanding of the role of lipoproteins in CVD. Furthermore, studies have shown that dyslipidemia may cause a decrease in $\mathrm{HDL}$ size as a result of depletion of large $\mathrm{HDL}$ and an increase in small HDL [18].

Our results show that patients with CVD have differences in lipid profile compared with that in CRF and control groups and that these differences affect plasma PON1 concentration (Figure 1).

Disturbed lipoprotein profile in CVD has been reported in several studies; however, in this study, the patients with CVD did not have disturbed lipoprotein profiles, probably because of the high use of statins in this group [19-21].

Emerging evidence in the literature underlines the impact of decreased serum PON1 activity on the development of atherosclerotic changes, but

Table II. Multinomial logistic regression analysis of HDL size stratified by status of obesity and dyslipidemia

\begin{tabular}{|c|c|c|c|c|c|}
\hline PON1 concentration $[\mu \mathrm{g} / \mathrm{ml}]$ & $\begin{array}{l}\text { Control }(n=21) \\
\operatorname{RRR}(95 \% \mathrm{Cl})\end{array}$ & $\begin{array}{l}\text { CRF }(n=22) \\
\operatorname{RRR}(95 \% \mathrm{Cl})\end{array}$ & $P$-value & $\begin{array}{l}\text { CVD }(n=26) \\
\operatorname{RRR}(95 \% \mathrm{Cl})\end{array}$ & $P$-value \\
\hline Non-obese & 1 (base group) & $1.1(0.9-1.3)$ & 0.31 & $0.18(0.08-0.4)$ & $<0.01$ \\
\hline Obese & 1 (base group) & $1.4(1.0-1.9)$ & 0.02 & $0.23(0.1-0.5)$ & $<0.01$ \\
\hline Non-dyslipidemic & 1 (base group) & $0.9(0.9-1.1)$ & 0.72 & $0.21(0.1-0.5)$ & $<0.01$ \\
\hline Dyslipidemic & 1 (base group) & $0.9(0.9-1.1)$ & 0.92 & $0.16(0.1-0.4)$ & $<0.01$ \\
\hline
\end{tabular}

Results are shown in terms of relative risk ratio (RRR). Cl 95\%=95 percent confidence interval.

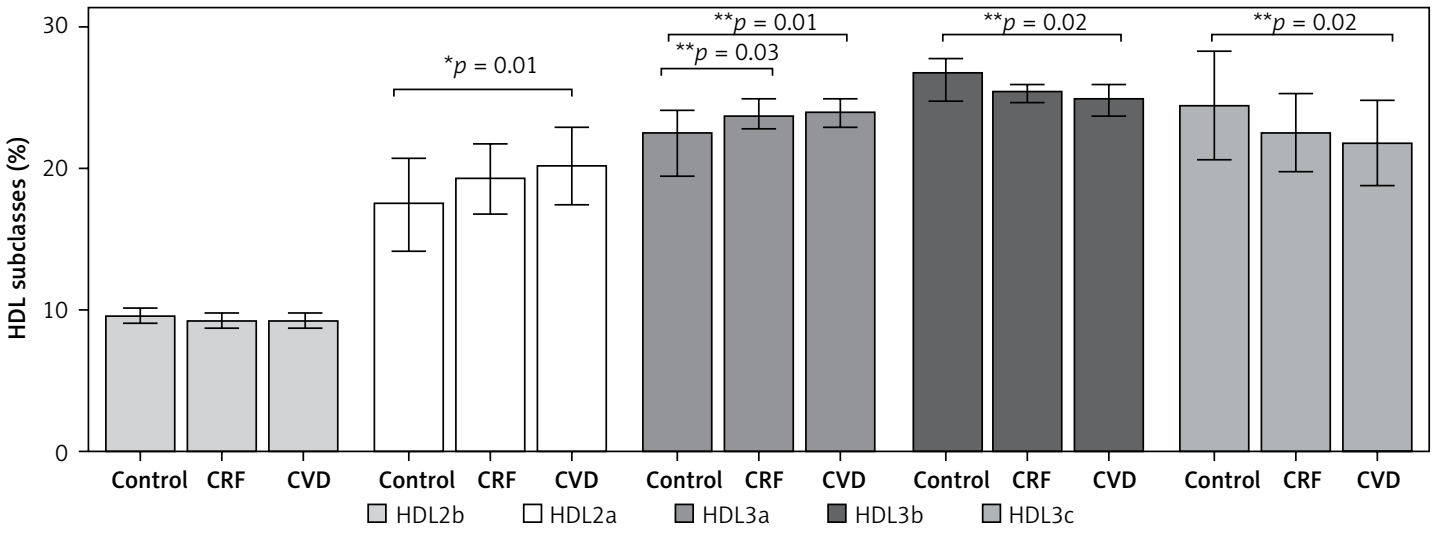

Figure 2. HDL subclasses of the three groups studied. Results are expressed as the relative proportion (mean \pm SD or median and interquartile range) of each HDL subclass calculated according to its migration distance in polyacrylamide gel and size intervals known for each HDL subclass. Comparisons between groups were made using ${ }^{*}$ ANOVA, Bonferroni test, or ${ }^{\star *}$ Kruskal-Wallis, Dunn test. Statistical significance level was accepted as $p<0.05$ 
few studies refer to PON1 concentration. Ikeda et al. [22] and Mackness et al. [23] reported a low PON1 concentration in coronary heart disease patients compared with healthy patients. Also, it has been demonstrated that decreased PON1 activity predicts a higher risk of major adverse cardiac events and that low serum concentrations of PON1 may be an independent predictor of cardiovascular mortality [22-26].

Our results of AREase activity did not show significant differences among the groups; it could be an effect of sample size. Low PON1 activity has been associated with 'low-quality' HDL, which implies a greater risk of developing diseases in which oxidative challenge and lipid peroxidation are involved, compared with individuals with high PON1 activity [10].

Current investigations indicate that the analysis of HDL subclasses and composition may improve the accuracy of CVD prediction [27]. Our results show that the control and CRF groups had a lower proportion of large HDL and higher proportion of small HDL compared with those with CVD. A negative correlation between HDL size and serum triglycerides was observed in the CRF group that had dyslipidemia (data not shown). Human population studies have shown that dyslipidemia in obesity and diabetes results in decreased HDL size because of the depletion of large HDL and an increase in small HDL [28]. The same results have been observed in Mexican adolescents [15]. These authors reported lower proportions of large HDL2a and HDL2b and a higher proportion of small HDL3b and HDL3c in hyperlipidemia compared to normolipidemia. Tian et al. [29] demonstrated that the plasma concentration of triglycerides has effects on the distribution of HDL subclasses. Moreover, patients who underwent statin therapy for 2 years experienced an increase in large HDL particles [30] and a reduction in serum PON1 [29].

It has been reported that the small HDL3 subclass carries a large proportion of the HDL antioxidant enzymes including PON1, whereas HDL2 is mostly involved in the removal of excess cellular cholesterol [30, 31]. In contrast, our results did not reveal an association between the concen-

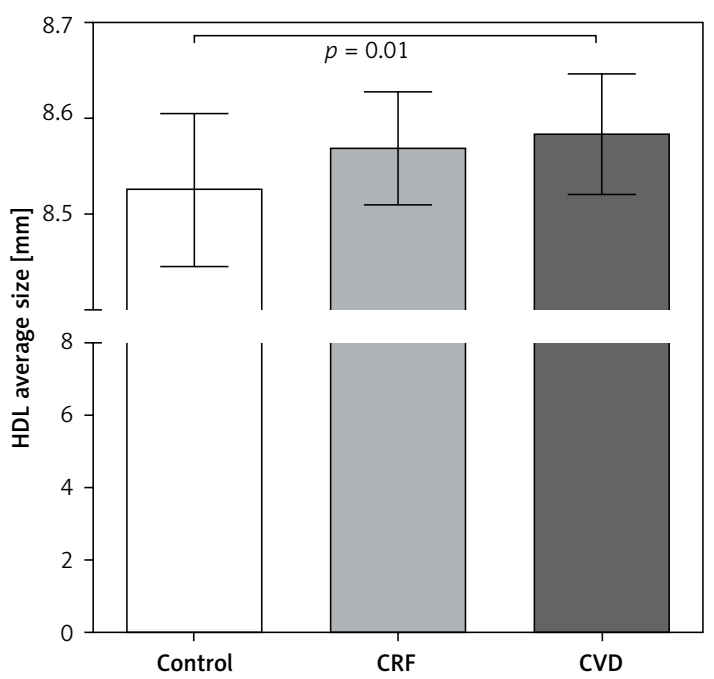

Figure 3. HDL sizes among groups. The average HDL particle size represents the overall distribution of the HDL subclasses and was calculated as the average size of each HDL subclass interval in $\mathrm{nm}$, multiplied by its relative area under the densitometric scan. Results are expressed as mean \pm SD. Comparisons between groups were made using ANOVA and Bonferroni test. Statistical significance level was accepted as $p<0.05$

tration of PON1 and large or small HDL subclasses, but a negative association between HDL size and PON1 concentration was found only in the control group. Also a higher PON1 concentration was found in smaller HDL compared with larger HDL. Medina-Urrutia et al. [16] found that patients with low HDL-C and high triglycerides had smaller HDL.

In conclusion, our data suggest that PON1 status and HDL characteristics could be early biomarkers that predict the potential for developing CVD.

One of the limitations of this study is the small sample size in the study groups, which increases the margin of error; however, the data presented in this work are important for future studies where the role of PON1 and HDL will be explored.

\section{Acknowledgments}

This work was supported by CONACyT Grant SSA/IMSS/ISSSTE-233745.

Table III. Multinomial logistic regression analysis of HDL size stratified by status of obesity and dyslipidemia

\begin{tabular}{|c|c|c|c|c|c|}
\hline $\begin{array}{l}\text { HDL average size } \\
\left(\mathrm{nm} \times 10^{-1}\right)\end{array}$ & $\begin{array}{l}\text { Control }(n=21) \\
\operatorname{RRR}(95 \% \mathrm{Cl})\end{array}$ & $\begin{array}{l}\operatorname{CRF}(n=22) \\
\operatorname{RRR}(95 \% \mathrm{Cl})\end{array}$ & $P$-value & $\begin{array}{l}\text { CVD }(n=26) \\
\operatorname{RRR}(95 \% \mathrm{Cl})\end{array}$ & $P$-value \\
\hline Non-obese & 1 (base group) & $1.17(1.0-1.3)$ & 0.01 & $1.23(1.1-1.4)$ & $<0.01$ \\
\hline Obese & 1 (base group) & $1.17(1.0-1.3)$ & 0.01 & $1.23(1.1-1.4)$ & $<0.01$ \\
\hline Dyslipidemic & 1 (base group) & $1.1(0.9-1.2)$ & 0.06 & $1.12(1.0-1.2)$ & 0.02 \\
\hline Non-dyslipidemic & 1 (base group) & $1.1(0.9-1.2)$ & 0.07 & $1.12(1.0-1.2)$ & 0.02 \\
\hline
\end{tabular}

Results are shown in terms of relative risk ratio (RRR). $95 \% \mathrm{Cl}-95$ percent confidence interval. 


\section{Conflict of interest}

The authors declare no conflict of interest.

\section{References}

1. WHO. (2017). Cardiovascular Diseases (CVDs). Retrieved January 4, 2018, from http://www.who.int/cardiovascular_diseases/en/.

2. WHF. (2017). Key facts of Cardiovascular Disease World Heart Federation. Retrieved January 5, 2018, from https://www.world-heart-federation.org/resources/key-facts/.

3. Lusis AJ. Atherosclerosis. Nature 2000; 407: 233-41.

4. Mackness M, Mackness B. Targeting paraoxonase- 1 in atherosclerosis. Expert Opin Therap Targets 2013; 17: 829-37.

5. Rached FH, Chapman MJ, Kontush A. HDL particle subpopulations: focus on biological function. Biofactors 2015; 41: 67-77.

6. Carreón-Torres E, Rendón-Sauer K, Monter-Garrido M, et al. Rosiglitazone modifies HDL structure and increases HDL-apo Al synthesis and catabolic rates. Clin Chim Acta 2009; 401: 37-41.

7. Rye KA, Barter PJ. Cardioprotective functions of HDLs. J Lipid Res 2014; 55: 168-79.

8. Camont L, Chapman MJ, Kontush A. Biological activities of HDL subpopulations and their relevance to cardiovascular disease. Trends Mol Med 2011; 17: 594-603.

9. Pérez-Méndez Ó, Pacheco HG, Martínez-Sánchez C, Franco M. HDL-cholesterol in coronary artery disease risk: function or structure? Clin Chim Acta 2014; 15: 111-22.

10. Mackness M, Mackness B. Human paraoxonase-1 (PON1): gene structure and expression, promiscuous activities and multiple physiological roles Gene 2015 ; 567: 12-21.

11. Deakin, SP, James RW. Genetic and environmental factors modulating serum concentrations and activities of the antioxidant enzyme paraoxonase-1. Clin Sci 2004; 107: 435-47.

12. Samouilidou E, Kostopoulos V, Liaouri A, et al. Association of lipid profile with serum PON1 concentration in patients with chronic kidney disease. Ren Fail 2016; 38: 1601-6.

13. DeLong D, DeLong E, Wood P, Lippel K, Rifkind BM. A comparison of methods for the estimation of plasma low- and very low-density lipoprotein cholesterol. JAMA 1986; 256: 2372-7.

14. Eckerson HW, Wyte CM, La Du BN. The human serum paraoxonase/arylesterase polymorphism. Am J Hum Genet 1983; 35: 1126-38.

15. Richter RJ, Jarvik GP, Furlong CE. Determination of paraoxonase 1 status without the use of toxic organophosphate substrates. Circ Cardiovasc Genet 2008; 1: 147-52.

16. Medina-Urrutia A, Juarez-Rojas JG, Martínez-Alvarado R, et al. High-density lipoprotein subclasses distribution and composition in Mexican adolescents with low HDL cholesterol and/or high triglyceride concentrations, and its association with insulin and C-reactive protein. Atherosclerosis 2008; 201: 392-7.

17. Deakin S, Moren X, James RW. HDL oxidation compromises its influence on paraoxonase- 1 secretion and its capacity to modulate enzyme activity. Arterioscler Thromb Vasc Biol 2007; 27: 1146-52.

18. Harangi M, Seres I, Harangi J, Paragh G. Benefits and difficulties in measuring HDL subfractions and human paraoxonase-1 activity during statin treatment. Cardio vasc Drugs Ther 2009; 23: 501-10.

19. Klop B, Elte JWF, Castro-Cabezas M. Dyslipidemia in obesity: mechanisms and potential targets. Nutrients 2013 5: 1218-40.

20. Totomoch-Serra A, Muñoz M de L, Burgueño J, RevillaMonsalve MC, Diaz-Badillo A. Association of common polymorphisms in the VEGFA and SIRT1 genes with type 2 diabetes-related traits in Mexicans. Arch Med Sci 2018; 14: 1361-73.

21. Jäger B, Piackova E, Haller PM, et al. Increased platelet reactivity in dyslipidemic patients with coronary artery disease on dual anti-platelet therapy. Arch Med Sci 2019; 15: 65-71.

22. Ikeda Y, Suehiro T, Itahara T, et al. Human serum paraoxonase concentration predicts cardiovascular mortality in hemodialysis patients. Clin Nephrol 2007; 67: 358-65.

23. Mackness B, Davies GK, Turkie W, et al. Paraoxonase status in coronary heart disease. Are activity and concentration more important than genotype? Arterioscler Thromb Vasc Biol 2001; 21: 1451-7.

24. Tang WH, Hartiala J, Fan Y, et al. Clinical and genetic association of serum paraoxonase and arylesterase activities with cardiovascular risk. Arterioscler Thromb Vasc Biol 2012; 32: 2803-12.

25. Sun T, Hu J, Yin Z, et al. Low serum paraoxonase 1 activity levels predict coronary artery disease severity. Oncotarget 2017; 8: 19443-54.

26. Mackness B, Marsillach J, Elkeles RS, et al. Paraoxonase- 1 is not associated with coronary artery calcification in type 2 diabetes: results from the PREDICT study. Dis Markers 2012; 33: 101-12.

27. McGarrah RW, Damian M, Haynes C, Dowdy E, Shah SH, Kraus WE. High-density lipoprotein subclass measurements improve mortality risk prediction, discrimination and reclassification in a cardiac catheterization cohort. Atherosclerosis 2016; 246: 229-35.

28. Asztalos BF, Collins D, Horvath KV, Bloomfield HE, Ro bins SJ, Schaefer EJ. Relation of gemfibrozil treatment and high-density lipoprotein subpopulation profile with cardiovascular events in the Veterans Affairs High-Density Lipoprotein Intervention Trial. Metabolism 2008; 57 77-83.

29. Tian L, Fu M. The relationship between high density lipoprotein subclass profile and plasma lipids concentrations. Lipids Health Dis 2010; 9: 118.

30. Rosenson RS, Otvos JD, Hsia J. Effects of rosuvastatin and atorvastatin on LDL and HDL particle concentrations in patients with metabolic syndrome: a randomized, double-blind, controlled study. Diabetes Care 2009, 32: 1087-91.

31. Miyamoto-Sasaki M, Yasuda T, Monguchi T, et al. Pitavastatin increases $\mathrm{HDL}$ particles functionally preserved with cholesterol efflux capacity and antioxidative actions in dyslipidemic patients. J Atheroscler Thromb 2013; 20: 708-16. 